\title{
ADAPTIVE PERFORMANCE: CONCEPTUAL MODEL IN INFORMATION SYSTEMS DOMAIN
}

\author{
Edgardo R. Bravo, Universidad del Pacifico-Lima-Peru, er.bravoo@up.edu.pe
}

\begin{abstract}
Organizations that are subject to increasingly dynamic environments need employees who adapt to changing demands (adaptive performance). Although the literature has studied this type of performance in recent years, the contribution of explanatory models in the context of information systems has been scarce. Based on the migration literature, the article proposes that the individual's intention of adaptive behavior (focused on improving his/her domain of the information system) is influenced by push factors (dissatisfaction, disconfirmation with his/her current domain), pull factors (expected benefits of improving his/her domain of the system), and mooring factors (self-efficacy, inertia, switching cost, and attitude toward the adaptation process). The results of this research may help management to design for change management strategies in the context of information systems.
\end{abstract}

Keywords: Adaptive Performance, Information Systems, Migration Theory, Intention

\section{INTRODUCTION}

Organizations today are characterized by change, which requires adaptive employees (Pulakos, Arad, Donovan, \& Plamondon, 2000, p. 612). Organizational literature defines adaptive performance as the degree to which an individual adapts to changes in the work system (Koopmans et al., 2011, p. 862). It describes the adaptation process as a sequence of four stages: perception of the situation (the individual perceives and interprets a situation and weighs it up as changing or stable); selection of the strategy (the individual seeks options to face the situation and chooses the appropriate strategy); handling of change (carrying out adaptive actions); and learning from the adaptive experience (Ployhart \& Bliese, 2006, p. 16).

The question then arises as to how individuals handle change in the context of information systems. The literature on implementation of information systems suggests that adaptation seeks to manage the situation generated by change through two mechanisms: adapting the technology - improving its features, and/or (2) adapting the individual improving his domain of the system by seeking support, consulting colleagues, attending training, etc. (LeonardBarton, 1988, p. 251; Tyre \& Orlikowski, 1994, p. 100). Other authors suggest that the individual also adapts by modifying his emotions (Beaudry \& Pinsonneault, 2005, p. 499). Empirical studies have followed this route (ElieDit-Cosaque \& Straub, 2011; Fadel, 2012). The problem is that these studies do not show in detail the individual and contextual factors that affect adaptive performance in IS domain. In that sense, the objective of this study is to conceptualize on adaptive performance and develop a model that explains its relevant antecedents in the context of information systems.

\section{BACKGROUND}

\section{Adaptation and Migration}

The notion of adaptation can be seen as a transition from an initial situation (current domain of an information system and/or current functionality of an information system) to another (improvement in domain and/or functionality). This notion of change of situation is not unique to the phenomenon of adaptation; it is also found in similar phenomena. The migration literature, for example, E. Lee (1966) focusses on the factors that lead an individual to migrate from one place (initial situation) to another (final situation). Similarly, the literature on marketing uses this notion to explain changing from one service provider (initial situation) to another (final 
situation) (Bansal, Taylor, \& James, 2005). The literature on information systems also uses this approximation to explain the change from one technology (current situation) to another (final situation) (Bhattacherjee \& Park, 2014). In all these phenomena (adaptation, migration, changing service provider and changing technology) attraction forces to the new situation can be seen, for example: improvement in performance, improvement in quality of life, improvement in the level of service, and improvement in technology features, respectively. In all these phenomena there are also forces to maintain the old situation. For example, attachment to routine, to family, to the service I already know or to the technology I already use, respectively. Moreover, in all these phenomena there are also barriers to the transition from the initial situation to the final one, such as the time and effort required to adapt, migrate, change of provider or change of technology. This parallelism is useful to resort to migration theory in general and of switching of provider and technology models in particular, as a basis for the formulation of a model that explains the adaptive behaviour.

\section{Theory of Migration}

Migration implies the movement of a person (the migrant) from one place to another for a given period. The theory of migration holds that migration arises due to three factors. The first of these encapsulates all the negative aspects of the current location that are an encouragement to leave it ("push factor"). Lack of employment, oppression due to political or religious beliefs, lack of opportunities for personal development, and natural disasters in the location are some of these aspects. The second factor summarizes all the positive aspects of the destination ("Pull Factor"). Better employment opportunities, higher levels of income or education, and better environmental conditions are some of the aspects in this factor. The third factor comprises personal, social or cultural aspects that may be a barrier (by extension also a facilitator) to the migration process ("Mooring factors"). Strong family ties, the costs in finance and time to migrate, and anxiety are some of the aspects included in this factor. For migration to occur, the net effect of the pull and push factors should be greater than the barriers set up by the mooring factors (E. Lee, 1966, p. 56; Moon, 1995, p. 504).

\section{CONCEPTUAL MODEL}

The migration model does not specify which factors are relevant to explain adaptation in the context of information systems. That is why the following paragraphs, based on the theory of migration applied to marketing and technology switching, develop the corresponding conceptual model. Given that there is a difference between factors that explain the adaptation of the individual and the adaptation of technology, this article will focus on explaining the adaptive performance of the individual. The conceptual model is shown in Figure 1. 


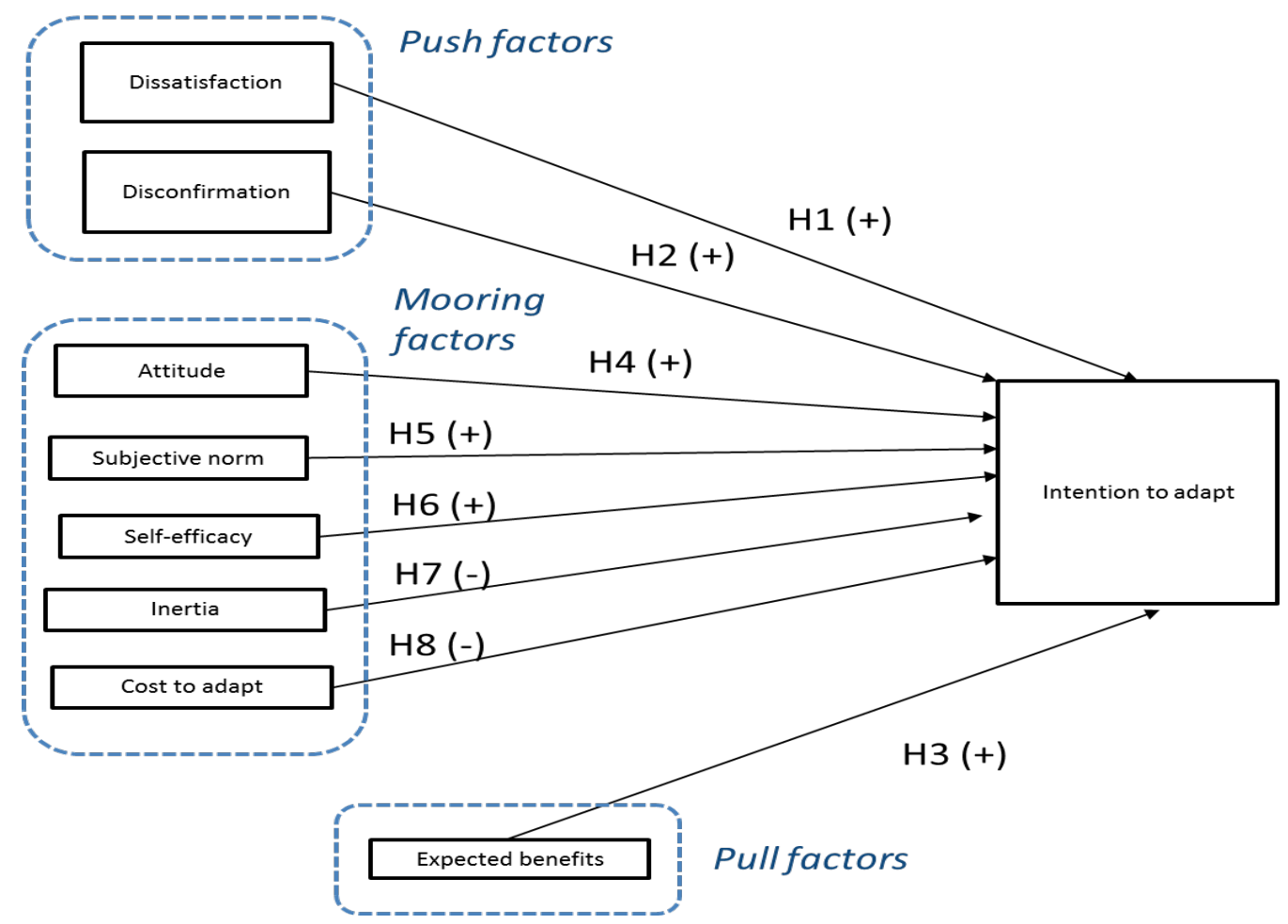

Figure 1. Research Model

\section{Push Factors}

According to the theory of migration, these factors are negative characteristics of the current location that influence the decision to migrate.

Dissastisfaction with the current provider or technology is a recurring push factor. Marketing proposes that dissatisfaction is a push factor towards changing provider (Bansal et al., 2005, p. 100). The relationship between dissatisfaction and the intention of provider switching is based on empirical evidence (Bansal \& Taylor, 1999b, p. 204; Cronin, Brady, \& Hult, 2000, pp. 197, 374). In information systems, it is suggested that dissatisfaction is one of the main reasons for switching technology (Parthasarathy \& Bhattacherjee, 1998, p. 367). Empirically, several authors have found evidence for the link between dissatisfaction and intention of use (Bhattacherjee \& Park, 2014, p. 366; Chang, Liu, \& Chen, 2014, p. 338).

In our model, dissatisfaction is conceived as an attitude and as such is a disposition of the individual with regard his/her current domain of the information system. Conceptually, dissatisfaction with the current domain of the information system would give rise to the intention (and subsequent behaviour) to overcome the situation. Attitude precedes behaviour such that, depending on how the dissatisfaction is valued, the individual will carry out actions to revert the discomfort (Eagly \& Chaiken, 2007, p. 591). In the theory of planned behaviour, attitudes are related to behaviour to the extent that they are individual evaluations (positive or negative) on performing said behaviour (Ajzen, 2005, p. 3).

On this basis it is possible to establish the following:

$\mathrm{H}_{1}$ : Dissatisfaction with current domain of the system has a positive effect on the intention to adapt.

Disconfirmation (the cognitive gap between expectations and perception after consuming the service of a provider or the use of a technology) is also a recurring push factor. In marketing, it has been shown empirically that poor quality 
affects the intention of switching the provider of banking services (Bansal et al., 2005, p. 108). In information systems, it has been shown that disconfirmation directly affects the intention of switching technology in mobile devices (T.-C. Lin \& Huang, 2014, p. 177).

In our model, disconfirmation is to be conceived as the individual's belief about the gap between his/her current domain of the information system and what the organisation would expect. Conceptually, disconfirmation with current domain of the information system gives rise to the intention (and subsequent behaviour) of eliminating the situation and in that sense, the individual will begin adaptive actions to improve his/her domain. According to the literature on job-person fit, a misfit between the demands of the task and the skills of the individual lead the individual to deploy adaptive behaviour to reduce the gap (Edwards, 1992, p. 244). Similarly, it is noted that the individual evaluates work demands in relation to his skills. If the demands exceed his/her skills and the gap proves threatening to the individual, then he will carry out actions to try improve the situation (Edwards, 1992, p. 244). On this basis, it can be proposed that:

$\mathrm{H}_{2}$ : Disconfirmation with current domain of the information system has a positive effect on the intention to adapt.

\section{Pull Factors}

According to the theory of migration, these factors correspond to positive characteristics of the destination that attract the potential migrant. The attractiveness of the new provider or the relative advantage of the new technology is a recurrent pull factor. In marketing, a study on bank clients finds empirical evidence of the relationship between attractiveness and intention of re-purchase (opposed to switching) (Jones, Mothersbaugh, \& Beatty, 2000, p. 267). In information systems, a number of studies empirically show the relevance of comparative advantage with regard to the intention of switching technology (Bhattacherjee \& Lin, 2015, pp. 366-370; H. Lin, Fan, \& Chau, 2014, p. 601). In our model, the expected benefit is to be understood as the individual's belief that an adaptive behaviour will increase his/her performance relative to his/her current situation. Conceptually, adaptation is a response to changes in the task that require an increase in specific knowledge and skills. It is considered that this increase contributes to re-establishing and/or improving the effectiveness and efficiency the individual had prior to the change (Baard, Rench, \& Kozlowski, 2014, p. 64). In this regard, adaptation may eventually lead to an improvement in the individual's performance (Koopmans et al., 2011, p. 863). It is possible that, to the extent that the individual adapts to emerging demands in the work environment, his subsequent results, effectiveness and efficiency may also improve. It is therefore expected that, to the extent that the individual considers that the adaptation will lead to an improvement in his effectiveness and efficiency, then he will undertake adaptive actions. On this basis, it is proposed that:

$\mathrm{H}_{3}$ : The perception of expected benefits has a positive effect on the intention to adapt.

\section{Mooring Factors}

In the theory of migration, these factors represent restrictions (or bridges) that hinder (or facilitates) the decision to migrate. They may be characteristics of the individual or barriers (or openings) to the migration process.

The constructs of attitude, subjective norms and perceived control behaviour in the Theory of Planned Behaviour (TPB) (Ajzen, 1991) are frequently cited as mooring factors. Attitude towards a behaviour is the general assessment, whether positive or negative, that the individual makes about carrying out said behaviour, and is determined by the beliefs about the possible consequences of carrying it out. The subjective norm is the social pressure perceived by the individual about carrying out a behaviour or not doing so, and is determined by the beliefs about the expectations and behaviours of the close and significant social circle. And perceived control is the degree of volitional control the individual has about carrying out a behaviour, and is determined by beliefs about the factors that may potentially facilitate or inhibit said behaviour (Ajzen, 1991, p. 183; 2005, p. 91). In marketing, attitude towards and perceived control of switch of provider have been linked to an intention to change. Empirical studies on switching bank in the case of mortgages find support for this relationship (Bansal \& Taylor, 1999b, p. 213; 2002, p. 418). In information systems, a study on switching internet browser (Ye \& Potter, 2011, p. 594) and another on migrating client-server applications to the cloud (Bhattacherjee \& Park, 2014, p. 366) find evidence for the effect of the subjective norm on intention to change. 
In our model, the attitude towards adaptation is conceived as the evaluation of the individual on the very process of adaptation. The subjective norm is to be understood as the social pressure on the individual to have an adaptive behaviour or not. Self-efficacy, one of the dimensions of perceived control, is defined as the perceived skill to perform an adaptive behaviour. According to the theory of planned behaviour, these three constructs, thus defined, should affect the intention to adapt. A study that explains the intention to continue learning the use of an Enterprise Resources Planning System (ERP) finds empirical evidence that supports the impact of attitude and subjective norm on intention (Chen, Razi, \& Rienzo, 2011, p. 162). Other studies that try to explain the intention to learn business skills in information technology professionals find that self-efficacy is a significant factor (T.-C. Lin, Wang, \& Wang, 2013, p. 1132).

On this basis, it is proposed that:

$\mathrm{H}_{4}$ : The attitude towards adaptive behaviour positively affects the intention to adapt.

$\mathrm{H}_{5}$ : The subjective norm related to adaptive behaviour positively affects the intention to adapt.

$\mathrm{H}_{6}$ : Self-efficacy related to adaptive behaviour positively affects the intention to adapt.

Inertia is a mooring factor cited in the models on switching provider and technology, and is relevant in the context of adaptation. In marketing, inertia is the tendency to continue buying a brand acquired in the past for two reasons: as opposed to searching for variety, or because the purchasing behaviours become unconscious patterns that facilitate the decision-making process (Kuo, Hu, \& Yang, 2013, p. 171; R. Lee \& Neale, 2012, p. 366). Empirically, a relationship is found between the search for variety (the opposite of inertia) and the intention of switching provider (Bansal et al., 2005, p. 103; Hou, Chern, Chen, \& Chen, 2011, p. 1900). In information systems, inertia is conceived as persisting in using the current information system (Polites \& Karahanna, 2012, p. 24). This implies the individuals reluctance to abandon an established information system, independently of whether there are alternatives in the present or the future. Empirically, there is evidence of a negative relation between inertia and the intention to change (T.-C. Lin \& Huang, 2014, p. 177; Polites \& Karahanna, 2012, p. 36).

In our model, given that the individual is subject to the options of adapting or maintaining current behaviour, we will take inertia as the persistence of existing behavior patterns, even if there are alternatives or incentives to change. Conceptually, when the individual perceives disconfirmation or dissatisfaction with his current domain of the system, he may tend to begin a process of adaptation. However, the mind-sets he usually uses may lead him to maintain the status quo (George \& Jones, 2001, p. 424). In keeping with the role of inertia present in the literature, we can suggest that:

$\mathrm{H}_{7}$ : Inertia has a negative effect on the intention to adapt.

The cost of carrying out a given behaviour (switching provider or technology) can become a barrier and is relevant in the context of adaptation. In marketing, the costs of change are those associated with the process of switching from one provider to another (Jones et al., 2000, p. 262). These costs may be procedural (time and effort that the change demands), financial costs and emotional costs of breaking ties with staff or identifying with the current provider (Burnham, Frels, \& Mahajan, 2003, pp. 111-112). These costs constitute a barrier to the intention of switching provider. Empirically, in the banking industry (Bansal et al., 2005, p. 108) and in laundry and hairdressing services (Bansal \& Taylor, 1999a, p. 77) there is evidence that supports the negative effect of costs on intention. In information systems, the costs of change are those relating to the process of switching one technology for another. A taxonomy for the costs of change of online services is also proposed: Relating to the provider (e.g. loss of financial resources that the individual will incur in changing provider) and relating to the user (user resources for a satisfactory change - effort and time in seeking information, assessing options, transfer to new provider - installing and configuring - and learning) (Ray, Kim, \& Morris, 2012, pp. 198-199). These costs have been linked as mooring factors in terms of the intention to switch technology. Empirically, in studies of migration to applications in the cloud (Bhattacherjee \& Park, 2014, p. 366), change of online games (Hou et al., 2011, p. 1900) and migration of blogs to social networks (Hsieh, Hsieh, Chiu, \& Feng, 2012, p. 1918) there is evidence in this regard. In our case, the switching cost is understood as the effort and time the individual must invest in order to improve his domain of the information system. 
Conceptually, when the individual perceives the need to increase his domain of the system, he may tends to begin an adaptation process. However, the time and effort that he must invest in said activity may discourage this impulse. In keeping with the role of the switching cost present in the literature, we can suggest the following:

$\mathrm{H}_{8}$ : The cost to adapt has a negative effect on the intention to adapt.

\section{DISCUSSION (EXPECTED RESULTS)}

It is expected that this model will show management the factors that may affect individuals in beginning adaptive behaviours in the context of information systems. It will thus be possible to develop strategies to manage adaptation. For example, the evaluation or self-evaluation schemes to be aware of the level of satisfaction and disconfirmation with regard to their domain of the system. Furthermore, the communication of what is expected of each employee and how domain of the system can affect results. In addition, the introduction of mechanisms to move individuals from their comfort zone (reflected in inertia). Likewise, establishing incentives that act on adaptation costs.

A questionnaire has been drawn up, based on existing scales, a pilot study has begun and data gathering is in process. Examples of items are shown in Annex. It is hoped to carry out data analysis through the structural equation model and report results as soon as possible.

\section{REFERENCES}

Ajzen, I. (1991). The theory of planned behavior. Organizational behavior and human decision processes, 50(2), 179-211.

Ajzen, I. (2005). Attitudes, personality, and behavior. UK: McGraw-Hill Education

Baard, S. K., Rench, T. A., \& Kozlowski, S. W. J. (2014). Performance adaptation: A theoretical integration and review. Journal of Management, 40(1), 48-99.

Bansal, H. S., \& Taylor, S. F. (1999a). Beyond service quality and customer satisfaction: Investigating additional antecedents of service provider switching intentions. Paper presented at the Proceedings of the 1999 Academy of Marketing Science (AMS) Annual Conference, Coral Gables, FL.

Bansal, H. S., \& Taylor, S. F. (1999b). The service provider switching model (spsm) a model of consumer switching behavior in the services industry. Journal of service Research, 2(2), 200-218.

Bansal, H. S., \& Taylor, S. F. (2002). Investigating interactive effects in the theory of planned behavior in a service-provider switching context. Psychology \& Marketing, 19(5), 407-425.

Bansal, H. S., Taylor, S. F., \& James, Y. S. (2005). "Migrating" to new service providers: Toward a unifying framework of consumers' switching behaviors. Journal of the Academy of Marketing Science, 33(1), 95-115.

Beaudry, A., \& Pinsonneault, A. (2005). Understanding user responses to information technology: A coping model of user adaptation. MIS Quarterly, 29(3), 493-524.

Bhattacherjee, A. (2001). Understanding information systems continuance: an expectation-confirmation model. MIS Quarterly, 25(3), 351-370.

Bhattacherjee, A., \& Lin, C.-P. (2015). A unified model of IT continuance: three complementary perspectives and crossover effects. European Journal of Information Systems, 24(4), 1-10.

Bhattacherjee, A., \& Park, S. C. (2014). Why end-users move to the cloud: A migration-theoretic analysis. European Journal of Information Systems, 23(3), 357-372. doi: 10.1057/ejis.2013.1 
Burnham, T. A., Frels, J. K., \& Mahajan, V. (2003). Consumer switching costs: A typology, antecedents, and consequences. Journal of the Academy of Marketing Science, 31(2), 109-126.

Cronin, J. J., Brady, M. K., \& Hult, G. T. M. (2000). Assessing the effects of quality, value, and customer satisfaction on consumer behavioral intentions in service environments. Journal of retailing, 76(2), 193-218.

Chang, I., Liu, C. C., \& Chen, K. (2014). The push, pull and mooring effects in virtual migration for social networking sites. Information Systems Journal, 24(4), 323-346.

Chen, K., Razi, M., \& Rienzo, T. (2011). Intrinsic factors for continued ERP learning: A precursor to interdisciplinary ERP curriculum design. Decision Sciences journal of innovative education, 9(2), 149-176.

Eagly, A. H., \& Chaiken, S. (2007). The advantages of an inclusive definition of attitude. Social Cognition, 25(5), 582-602.

Edwards, J. R. (1992). A cybernetic theory of stress, coping, and well-being in organizations. Academy of management review, 17(2), 238-274.

Edwards, J. R., Cable, D. M., Williamson, I. O., Lambert, L. S., \& Shipp, A. J. (2006). The phenomenology of fit: linking the person and environment to the subjective experience of person-environment fit. Journal of Applied Psychology, 91(4), 802.

Elie-Dit-Cosaque, C. M., \& Straub, D. W. (2011). Opening the black box of system usage: User adaptation to disruptive IT. European Journal of Information Systems, 20(5), 589-607.

Fadel, K. J. (2012). User adaptation and infusion of information systems. Journal of Computer Information Systems, 52(3), 110.

George, J. M., \& Jones, G. R. (2001). Towards a process model of individual change in organizations. Human Relations, 54(4), 419-444.

Hou, A. C., Chern, C.-C., Chen, H.-G., \& Chen, Y.-C. (2011). Migrating to a new virtual world: Exploring MMORPG switching through human migration theory. Computers in Human Behavior, 27(5), 1892-1903.

Hsieh, J.-K., Hsieh, Y.-C., Chiu, H.-C., \& Feng, Y.-C. (2012). Post-adoption switching behavior for online service substitutes: A perspective of the push-pull-mooring framework. Computers in Human Behavior, 28(5), 1912-1920.

Jimmieson, N. L., Peach, M., \& White, K. M. (2008). Utilizing the theory of planned behavior to inform change management. Journal of Applied Behavioral Science, 44(2), 237-262.

Jones, M. A., Mothersbaugh, D. L., \& Beatty, S. E. (2000). Switching barriers and repurchase intentions in services. Journal of retailing, 76(2), 259-274.

Koopmans, L., Bernaards, C. M., Hildebrandt, V. H., Schaufeli, W. B., de Vet, H. C. W., \& van der Beek, A. J. (2011). Conceptual frameworks of Individual work performance: A systematic review. Journal of Occupational and Environmental Medicine, 53(8), 856-866.

Kuo, Y.-F., Hu, T.-L., \& Yang, S.-C. (2013). Effects of inertia and satisfaction in female online shoppers on repeat-purchase intention: The moderating roles of word-of-mouth and alternative attraction. Managing Service Quality: An International Journal, 23(3), 168-187.

Lee, E. (1966). A theory of migration. Demography, 3(1), 47-57.

Lee, R., \& Neale, L. (2012). Interactions and consequences of inertia and switching costs. Journal of Services Marketing, 26(5), 365-374. 
Leonard-Barton, D. (1988). Implementation as mutual adaptation of technology and organization. Research Policy, 17(5), 251-267.

Lin, H., Fan, W., \& Chau, P. Y. K. (2014). Determinants of users' continuance of social networking sites: A self-regulation perspective. Information \& Management, 51(5), 595-603.

Lin, T.-C., \& Huang, S.-L. (2014). Understanding the Determinants of Consumers' Switching Intentions in a Standards War. International Journal of Electronic Commerce, 19(1), 163-189.

Lin, T.-C., Wang, Y.-S., \& Wang, Y.-Y. (2013). Exploring the determinants of IS developers' behavioural intention to learn business skills. Behaviour \& Information Technology, 32(11), 1125-1138.

Moon, B. (1995). Paradigms in migration research: Exploring "moorings" as a schema. Progress in Human Geography, 19(4), 504.

Parthasarathy, M., \& Bhattacherjee, A. (1998). Understanding post-adoption behavior in the context of online services. Information Systems Research, 9(4), 362-379.

Ployhart, R. E., \& Bliese, P. D. (2006). Individual adaptability (I-ADAPT) theory: Conceptualizing the antecedents, consequences, and measurement of individual differences in adaptability. In S. Burke, L. Pierce \& E. Salas (Eds.), Understanding adaptability: A prerequisite for effective performance within complex environments (pp. 3-39). St. Louis, MO: Elsevier Science.

Polites, G. L., \& Karahanna, E. (2012). Shackled to the status quo: The inhibiting effects of incumbent system habit, switching costs, and inertia on new system acceptance. MIS Quarterly, 36(1), 21-A13.

Pulakos, E. D., Arad, S., Donovan, M. A., \& Plamondon, K. E. (2000). Adaptability in the workplace: Development of a taxonomy of adaptive performance. Journal of Applied Psychology, 85(4), 612.

Ray, S., Kim, S. S., \& Morris, J. G. (2012). Research note-online users' switching costs: Their nature and formation. Information Systems Research, 23(1), 197-213.

Tsay, H.-H. C. (2015). Encouraging IS developers to learn business skills: An examination of the MARS model. Information Technology and People.

Tyre, M. J., \& Orlikowski, W. J. (1994). Windows of opportunity: Temporal patterns of technological adaptation in organizations. Organization Science, 5(1), 98-118.

Ye, C., \& Potter, R. (2011). The role of habit in post-adoption switching of personal information technologies: An empirical investigation. Communications of the Association for Information Systems, 28(1), 585-610. 


\section{APPENDIX \\ ITEMS AND SCALE SOURCES}

\begin{tabular}{|c|c|c|}
\hline Construct & $\begin{array}{l}\text { Example of Item } \\
\end{array}$ & Source \\
\hline Dissatisfaction & $\begin{array}{l}\text { How do you feel about your current domain of the } \\
\text { system? Very dissatisfied... Very satisfied. }\end{array}$ & (Bansal et al., 2005; Bhattacherjee, 2001) \\
\hline Disconfirmation & $\begin{array}{l}\text { The degree of your current domain of the system } \\
\text { regarding: how to use the system's functionality. } \\
\text { (Much less than adequate ... much more than } \\
\text { adequate) }\end{array}$ & $\begin{array}{c}\text { (Edwards, Cable, Williamson, Lambert, \& } \\
\text { Shipp, 2006) }\end{array}$ \\
\hline Attitude & $\begin{array}{l}\text { Improve my current domain of the system would } \\
\text { be: Very foolish ... Very wise. }\end{array}$ & $\begin{array}{c}\text { (Bansal et al., 2005; Jimmieson, Peach, \& } \\
\text { White, 2008) }\end{array}$ \\
\hline Subjective Norm & $\begin{array}{l}\text { People who are important to me think I should } \\
\text { improve my current domain of the system. }\end{array}$ & (Bhattacherjee \& Park, 2014) \\
\hline Self-efficacy & $\begin{array}{l}\text { I have the ability to improve my current domain } \\
\text { of the system. }\end{array}$ & (T.-C. Lin et al., 2013; Tsay, 2015) \\
\hline Inertia & $\begin{array}{l}\text { Even though I can improve my domain of the } \\
\text { system, I will continue with my current domain of } \\
\text { the system...because it would be stressful to } \\
\text { change. }\end{array}$ & $\begin{array}{l}\text { (T.-C. Lin \& Huang, 2014; Polites \& Karahanna, } \\
\text { 2012) }\end{array}$ \\
\hline Cost to adapt & $\begin{array}{l}\text { It will take me a lot of time to improve my current } \\
\text { domain of the system. }\end{array}$ & (Bhattacherjee \& Park, 2014) \\
\hline Expected benefits & $\begin{array}{l}\text { Compared to my current domain of the system: A } \\
\text { better domain of the system will improve my } \\
\text { performance. }\end{array}$ & (Ye \& Potter, 2011)) \\
\hline Intention to adapt & $\begin{array}{l}\text { I intend to gradually improve my current domain } \\
\text { of the system in the foreseeable future. }\end{array}$ & (Bhattacherjee \& Park, 2014) \\
\hline
\end{tabular}

